\title{
Transit-Induced Gentrification: Who Will Stay, and Who Will Go?
}

\author{
Casey Dawkins \\ National Center for Smart Growth \\ University of Maryland \\ dawkins1@umd.edu \\ Rolf Moeckel \\ National Center for Smart Growth \\ University of Maryland \\ moeckel@umd.edu
}

Presented at the

Transit, Transit Oriented Development, and Urban Form:

A Bi-National Symposium Featuring Paris, France, and Washington, DC

October 18, 2014

\section{DRAFT}

Note: Results from the SILO model simulations discussed in the paper are forthcoming. 


\section{Introduction}

Transit-Oriented Development (TOD) has been promoted by planners and policy advocates as a solution to a variety of urban problems, including automobile traffic congestion, air pollution, and urban poverty. By mixing residential and commercial land uses at high densities near transit stations, TODs can theoretically enhance access to jobs and other urban activities for those living within walking distance of a transit stop. Since poverty-stricken families often lack access to an automobile, TOD is seen as a particularly important piece of the puzzle linking unemployed persons to job opportunities. The new Sustainable Communities Partnership between the U.S. Department of Housing and Urban Development (HUD), the U.S. Environmental Protection Agency (EPA), and the U.S. Department of Transportation (DOT) aims to capitalize on these benefits to promote more sustainable and equitable development patterns through TOD-based land use strategies (Federal Transit Administration, U.S. Department of Transportation 2008).

Since the enhanced accessibility offered by transit proximity is often capitalized into land and housing prices, many express concern that new transit investments will result in the displacement of the low income populations likely to benefit most from transit access, a phenomenon which we term "transit-induced gentrification." In response to these concerns, policy advocates at the local, state and federal level have proposed a variety of policy interventions designed to ensure that affordable housing for low to moderate income households is produced and preserved in areas proximate to transit stations. For example, in Denver, Colorado, a TOD Fund was established to support the creation and preservation of over 1,000 affordable housing units through the strategic acquisition of properties in current and planned transit corridors. Another example is the Transit-Oriented Development Housing Program approved by California voters through Proposition 1C in November 2006. The TOD Housing 
Program provides $\$ 2.85$ billion for housing and infrastructure programs. To qualify for this funding, developments must be within one half mile of a transit station, and 15 percent of units must be affordable to low- or very-low-income households (Dawkins and Buehler 2010). California is also one of several states that award additional points to Low Income Housing Tax Credit (LIHTC) applications that propose new affordable housing near public transit stations. Local jurisdictions around the country, including several in the Washington, D.C. region, rely on inclusionary zoning strategies to award density bonuses to developers proposing affordable housing projects near transit stations. Despite the interest in such measures among policy advocates, little is known about the effectiveness of these policy proposals. This paper addresses the question: How do TOD-based affordable housing policies influence the intra-urban location of low income households over time?

This paper relies on the Simple Integrated Land-Use Orchestrator (SILO) land use model to simulate the impact of various housing policy proposals on the current and future spatial pattern of household income near existing and proposed public transit stations and throughout the Washington, D.C. metropolitan area. In contrast to conventional land use models, SILO explicitly accounts for household relocation constraints, considering housing costs, transportation costs, and travel times. Should the travel or housing budget of a household be exceeded, relocation to a less expensive dwelling or a location with lower transportation costs is triggered in the model. As a result, SILO is a particularly useful tool for simulating the impact of policy scenarios.

The paper is organized as follows: The next section reviews the literature on the linkages among public transportation, housing affordability, and household sorting by income. We then discuss the SILO model and describe the policy simulations to be explored for the Washington, 
D.C. region. Following this discussion, we present a descriptive case study of historical patterns of income sorting within the Washington, D.C. region, followed by a description of the SILO policy scenario simulation results. The final section offers concluding observations.

\section{Background}

Transit-Oriented Development (TOD) is gaining popularity in U.S. metropolitan areas. Between the 2000 Decennial Census and the 2009 American Community Survey, the number of commuters relying on public transit increased by 18\% (American Public Transit Association 2010). Population forecasts also suggest that demographics in the U.S. are changing in ways that may enhance the popularity of living near transit, as the demographic groups growing most quickly (older, non-family, white households) have historically relied on transit in higher numbers. A report commissioned by the Federal Transit Administration estimates that the demand for transit-accessible housing will double to 14.6 million households by the year 2030 (Thorne-Lyman et al. 2008).

Part of the appeal of TOD is its broad-base of political support. According to Altshuler and Luberoff (2003), "It appeals to interests across the political spectrum: downtown and construction-related businesses, construction and transit labor unions, environmentalists, goodgovernment organizations, advocates for the poor, and a wide variety of others who perceive transit as a way of reconciling development, equity and amenity goals" (Altshuler and Luberoff 2003, p. 217; cited in Kahn (2007)). This level of support helps to justify transit investments that often require outlays of billions of dollars that are rarely recouped through fare-box revenues alone. 
The growing popularity of and support for TOD implies that households and businesses who value transit proximity will place upward pressure on land and housing prices in transitaccessible areas. Low-income households are less likely to rely on automobiles to reach employment and other destinations and are thus more dependent on reliable access to public transit. Many express concern that absent market intervention, profit-maximizing developers will seek the highest valued land uses for their projects, which will result in the gentrification of TODs and displacement of low income populations in areas accessible to transit. The literature reviewed in this section explores the theory and evidence linking transit investments, housing prices, and intra-urban income sorting.

\section{Theory and Evidence}

New public transportation investments confer benefits to owners of property located proximate to new transit stations. Those who value the increased accessibility provided by transit will bid up land prices in areas proximate to transit, thereby placing upward pressure on housing prices in those areas. Empirical evidence suggests that proximity to public transit is capitalized into the price of land and housing, although the extent of the estimated housing price increase varies considerably by study. Cervero et al.'s (2004) literature review concludes that home prices are within 6 to 45 percent higher near transit stations than around otherwise equivalent sites. A more recent meta-analysis that controls for study characteristics suggests that residential properties located within $1 / 4$ mile of public transit stations command a roughly $4.2 \%$ higher price than other properties, controlling for other housing and neighborhood characteristics (Debrezion et al. 2007). This meta-analysis concludes that commuter railway stations are found to have a consistently higher positive impact on property values than light and heavy rail stations. 
Other studies suggest that housing price increases differ for high income versus low income neighborhoods. Consistent with the TOD-induced gentrification argument, Immergluck (2009) finds that housing prices increased 15 to 30 percent in low income neighborhoods proximate to new planned stations in Atlanta, while housing prices either remained the same or declined in high income neighborhoods proximate to transit. Kahn (2007) reports similar findings in a study conducted across a larger number of metropolitan areas. Other evidence suggests just the opposite. Hess and Almeida (2007), Bowes and Ihlanfeldt (2001), and Gatzlaff and Smith (1993) find that housing price increases are actually higher in high-income station areas, particularly if these areas also include other desirable neighborhood retail and commercial amenities.

Fewer empirical studies directly examine the impact of transit investments on patterns of intra-urban sorting by income, and the theoretical link between accessibility, transit, and the intra-urban distribution of different income groups is more ambiguous. The monocentric urban land use model (Muth 1969; Mills 1972; Alonso 1964) predicts that accessibility to centralized employment is capitalized into land and housing prices. When making a location decision, households make tradeoffs between the increased accessibility offered by more central locations and the higher housing prices in those areas. Assuming that housing markets are competitive, and residents face no constraints to purchasing homes in central city or suburban housing markets, low income households will reside on the most expensive and accessible land when the income elasticity of housing demand exceeds the income elasticity of leisure time, which requires that the income elasticity of housing demand exceeds one (Becker 1965). When this assumption is met, poor households will outbid rich households for land in the most accessible 
areas, because poor households place a higher value on leisure time relative to housing consumption, even though housing is more expensive in those areas.

Empirical evidence does not fully support the monocentric model's restrictive assumption about income elasticities for housing and leisure demand. Most studies conclude that the income elasticity of demand for housing is far less than one, which implies that high income households may place a higher value on intra-urban accessibility than low income households (Mayo 1980). Evidence examining the monocentric model's sorting predictions provides similarly mixed results regarding the intra-distribution of household income. In one of the early tests of the income-sorting implications of the monocentric model, Wheaton (1977) estimates bid-rent functions for different income groups and finds no significant difference between those of higher and lower income households.

LeRoy and Sonstelie (1983) and Glaeser, et al. (2008) suggest that even if the monocentric model's assumptions are not met, low income households may still outbid higher income households for housing in more accessible locations near public transit if low income households are less likely to own automobiles and value proximity to transit more highly than high income households. Glaeser et al. (2008) present empirical evidence which suggests that the desire to live near transit is an important factor explaining the centralization of povertystricken households in urban areas. Gin and Sonstelie (1992) examine historical data from Philadelphia in the late 1800 s after the introduction of the streetcar and find that low income households had steeper bid rent functions and were more likely to centralize than high income households, because low income households were unable to afford the higher costs associated with commuting by streetcar. Baum-Snow and Kahn (2005) examined data from 16 metropolitan areas that expanded rail service between 1970 and 2000 and found that average 
household income was lower in areas with new transit access than in other areas within the same metropolitan area. Consistent with Glaeser et al. (2008), the authors conclude that during this time period, transit acted as a "poverty magnet."

Two other recent studies provide mixed evidence of transit-induced gentrification within some metropolitan areas. Kahn (2007) examines data from 14 metropolitan areas before and after the introduction of new transit stations and finds evidence of transit-induced gentrification in some transit-proximate areas. Specifically, the authors find that some "walk and ride" stations attract households who are more likely to hold college degrees. Neighborhoods near "park and ride" stations, on the other hand, often saw increases in poverty. The authors also find that these effects vary significantly by metropolitan area, with the strongest gentrification effects observed in Boston and Washington, D.C. Pollack et al. (2010) examined data for census block groups that introduced new rail systems between 1990 and 2000 and found that in more than three fifths of the neighborhoods studied, median household income increased more than in the surrounding metropolitan area. Indirect evidence of TOD-induced gentrification is provided by Pucher and Renne (2003), who point to gentrification around transit stations as an explanation for the increase in transit ridership among high income households and the reduction in transit ridership among low income households between 1995 and 2001.

To our knowledge, outside of case studies examining specific transit developments, no studies have examined the effectiveness of various policies designed to encourage affordable housing near transit to determine how these policies influence the income distribution both within TODs and metro-wide. The primary contribution of our paper is to provide an estimate of how households of different incomes make tradeoffs between housing consumption and transportation costs under different housing policy regimes. 


\section{Simulation Methodology}

This section describes the SILO microsimulation model that is used to examine the impact of various housing policy scenarios on patterns of spatial sorting by income within the Washington, D.C. region. Following a brief description of the model, we discuss the approach taken to generate various policy scenarios.

\section{$\underline{\text { Overview of SILO }}$}

SILO is a land-use model that is designed as a discrete choice microsimulation model. Discrete choice means that decisions (such as a decision of a household to move to a new dwelling) are modeled explicitly based on the benefit or utility at the current dwelling location and expected utilities at alternative dwelling locations. SILO is a microsimulation model, and therefore, every household, person, and dwelling is treated as an individual object.

Insert Figure 1 here

To initiate the model, a synthetic population is created for the base year 2000. The Public Use Micro Sample (PUMS) 5\% dataset is used to create this synthetic population. Using expansion factors provided by PUMS, household records with their dwelling are duplicated until the population by PUMS zone (called PUMA) matches 2000 census data. The location is disaggregated from PUMA to model zones using the socio-economic data from the Maryland Statewide Transportation Model (MSTM) as a weight. Work places are created based on MSTM zonal employment data. For each worker, a work location is chosen based on the average 
commute trip length distribution found in the 2007-2008 TPB/BMC Household Travel Survey.

SILO simulates the following events that may occur to persons, households, and dwellings:

- Household

○ Relocation

○ Buy or sell cars

- Person
$\circ$ Aging
○ Leave parental household
○ Marriage
○ Birth to a child
○ Divorce
$\circ$ Death
○ Find a new job
○ Get laid off

- Dwelling
- Construction of new dwellings
- Renovation
○ Deterioration
○ Demolition
- Increase or decrease of price 
Being a microsimulation model, every household and person is simulated individually. SILO models household relocation, non-spatial demographic changes (such as birth, aging, marriage or having children), developers' decisions to build new residential buildings and change of dwellings over time (including renovation, deterioration and demolition). The model is calibrated to closely match observed land use changes from 2000 to 2010 (so-called backcasting), to reasonable model population changes in the future to the year 2030. SILO is built as a middle-weight tool. It is fully integrated with a travel demand model, and therefore, more complex than sketch-planning tools (such as CommunityViz or UPlan). On the other hand, it is built to function with less rigorous data collection and estimation requirements than traditional large-scale land-use models (such as PECAS or UrbanSim), making SILO simpler to implement.

All decisions that are spatial (household relocation and development of new dwellings) are modeled with Logit models. Initially developed by Domencich \& McFadden (1975), such models are particularly powerful at representing the psychology behind decision making. Other decisions (such as getting married, giving birth to a child, leaving the parental household, upgrading an existing dwelling, etc.) are modeled by Markov models that apply transition probabilities.

SILO has been designed in a modular layout. This allows adding or disabling selected modules. For example, the user may decide to use the demographic change module of SILO but the household relocation module of another land use model. At the beginning of every simulation period, events are created that are executed in random order. Somewhere, a child is born, someone else celebrates her birthday, elsewhere a new dwelling is built, some people get 
married, etc. By executing events in random order, path dependency is avoided and events may affect each other as they do in real life.

SILO is an open-source software and was initially developed with funding by Parsons Brinckerhoff. The prototype application was implemented for the Metropolitan Area of

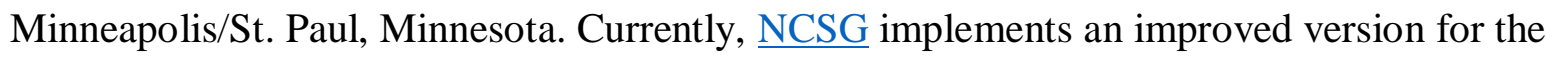
State of Maryland. SILO provides a GUI (Graphical User Interface) to facilitate model applications. A visualization tool allows easy analysis of model results.

For this particular application, SILO has been integrated with the Maryland Statewide Transportation Model (MSTM). The MSTM is a state-of-practice 5-step travel demand model, including trip generation, destination choice, mode choice, time-of-day choice and network assignment. The MSTM provides zone-to-zone travel times by auto and by transit to SILO, and SILO in turn provides the location of households at the zonal level.

\section{$\underline{\text { Policy Scenarios }}$}

We rely on SILO to forecast housing and transportation outcomes to the year 2030. The key focus of the simulations is the spatial distribution of household income, emphasizing the manner in which incomes vary with proximity to existing and planned transit stations. To evaluate the impact of policy scenarios, we perform the following simulations:

1. Baseline Scenario. The baseline scenario assumes a "business as usual" case reflecting the continuation of existing spatial development policies, assuming that developers construct sufficient housing to meet the demand for housing. 
2. TOD Affordable Housing Scenario. Under this scenario, we assume that a regional inclusionary housing program is in place such that $15 \%$ of all new residential development near public transit stations is priced within a range that is affordable to households earning $60 \%$ of the Area Median Income. We assume that these units will remain affordable throughout the simulation period. This scenario is similar in concept to policies currently in place within Arlington, Virginia, and Montgomery County, Maryland.

3. Compact Development Scenario. Under this scenario, we assume that the majority of all new development in the region is concentrated within the "activity centers" designated in the Washington, D.C. "Region Forward" Plan, a recently-adopted plan outlining future development goals for the Washington, D.C. metropolitan area. In contrast to scenario 2, this scenario does not assume specific affordability targets, but rather, assumes that developers will economize on higher cost land near activity centers by increasing the supply of smaller multi-family units.

4. Combined Scenario. Here we assume that the region adopts a TOD affordable housing strategy along with a compact development strategy. This strategy represents the combined impact of scenarios 2 and 3 above.

\section{Washington, D.C. Case Study}

We begin with an exploration of recent trends in housing prices and income sorting within transit-proximate Washington, D.C. neighborhoods. Rising housing prices in the Washington, D.C. metropolitan area have placed significant pressure on the region's supply of affordable housing. One recent study by the Urban Institute found that for every 100 extremely low income renter households living in the District of Columbia, there are only 45 units affordable and 
available (http://www.urban.org/housingaffordability/). Another recent study found that within the Washington D.C. metropolitan area, 44 percent of the region's federally assisted housing is located within one-half mile of public transit nodes. However, approximately 67 percent of the region's 10,569 subsidized units near transit have contracts that will expire in 2014, suggesting that rising housing prices in the region may place pressure on the region's subsidized housing near transit (Harrell et al. 2009). Figure 2 below (from Dawkins and Buehler 2010) displays the location of public transit stations in Washington, D.C., along with the distribution of average rents and the location of Low Income Housing Tax Credit (LIHTC) properties. The LIHTC program is currently the largest federal program supporting affordable housing construction.

Figure 2

As illustrated in this figure, the distribution of rental prices within the D.C. region is sharply divided along East-West lines, with the largest rents in Northwest D.C. and Southeastern Maryland near Bethesda. LIHTC properties are distributed throughout the region, with the largest concentration near transit located in upper Northwest D.C. near the $14^{\text {th }}$ Street corridor and in Southwest D.C. in Anacostia. Figure 2 also displays the location of each transit line in the Metro system.

The Washington D.C. Metrorail (Metro) system is managed by the Washington Metropolitan Transit Authority (WMATA), established in 1967 by an interstate compact authorizing WMATA to plan, develop, build, and finance a regional rail and bus transit system. The first rail stations were opened along the Red Line in 1976. Today, the system serves 86 stations and has 106 miles of track (Washington Metropolitan Area Transit Authority 2010). 
Two additional lines are under development along the Virginia Silver Line and the Maryland Purple Line.

The Metro system has expanded considerably since the 1970s. The first lines were constructed along the Red Line which initially served downtown D.C. and the Orange / Blue Lines which connected Virginia to Federal Center Southwest and portions of Prince George's County, Maryland. In all, 37 stations were constructed between 1976 and 1979. During the 1980s, Metro expanded service along the Red Line into Montgomery County, Maryland, and added new service along the Yellow Line in Alexandria, Virginia. A total of 24 stations were added during the 1980s. 17 new stations were added during the 1990s linking portions of Northwest DC to Greenbelt, Maryland. In the 2000s, 8 additional stations were added along the Green, Red, and Blue Lines (Washington Metropolitan Area Transit Authority 2010). This variation in station opening times allows us to examine trends in household income before and after station openings to identify how station development influenced historical patterns of sorting by income.

Figures 3-6 below display the percentage decadal changes in median household income at the census tract level for all D.C.-area jurisdictions where metro stations are located. We rely on the Longitudinal Tract Database provided by Brown University to display longitudinal changes in household income, holding Census geographies constant at 2010 tract boundaries. In each map, metro stations are indicated by dots that are colored according to the decade in which stations were opened. Existing studies of the housing price impacts of station development suggest that the announcement of station development often has a more significant impact on prices than the opening of the station itself (Knaap et al. 2001). Conversely, price increases may be delayed near certain stations if retail and other amenities are slow to emerge near station areas 
(Kahn 2007). To capture each of these effects on patterns of household sorting by income, we examine trends in household income before, during, and after station openings.

Insert Figures 3-6

As illustrated in Figure 3, many census tracts in the D.C. region saw large percentage increases in household income during the 1970s. Those tracts near 1970s-era transit station openings which saw the largest increases are located in Downtown D.C. and Arlington, Virginia. Tracts adjacent to Orange Line stations constructed in Prince George's County, Maryland saw smaller increases in household income. During the 1980s (Figure 4), the largest increases in household income were in Montgomery County, Maryland, and Western Fairfax County, Virginia. Tracts along the new Red Line extension also saw relatively large increases in household income, as did tracts located proximate to the new Orange and Yellow line extensions in Virginia. During the 1990s, household income growth slowed for most census tracts, yet along the Montgomery County Red Line, household income was continuing to grow at a faster pace than tracts located farther from transit stations. Figure 5 illustrates that tracts located proximate to transit stations constructed during the 1990s did not see the same proportionate income growth as tracts located near stations constructed in earlier decades. Fewer stations were constructed during the 2000s, and as shown on Figure 6, some tracts proximate to transit saw higher income growth than others. The highest income growth near transit stations opening in the 2000s occurred near the NoMa station in Northeast D.C. and around new Green Line stations in Southwest D.C. 
We now turn to a graphical display of changes in household income by decade. Figures 7-10 display the percentage change in household income for census tracts that were never within $1 / 2$ mile of a transit stop versus those that were within $1 / 2$ mile of a transit stop that opened in each decade. We exclude census tracts that were located within $1 / 2$ mile of stations that opened in several decades from the analysis to isolate the impact of openings in a single decade. Separate figures are presented for each decade when stations opened to examine income changes before, during, and after station openings. As Figure 7 demonstrates, while most census tracts saw large percentage increases in median household income within the 1970s, the percentage change in median household income within census tracts that were proximate to stations that opened in the 1970s was 27 percentage points higher than in other census tracts. This increase persisted until the 1980s, and by the 1990s, income growth was comparable for transit-accessible census tracts compared to other census tracts.

Insert Figures 7-10

Figure 8 makes the same comparison, emphasizing differences with respect to census tracts that were located near transit stations that opened in the 1980s. While tracts accessible to stations opening in the 1980s actually saw smaller increases in median household income during the 1970s, these same tracts saw a higher percentage increase in household income during the period in which transit stations were opened. Furthermore, these higher rates of income growth persisted until the 2000 s.

Figure 9 emphasizes stations that were opened during the 1990s. In contrast to the results displayed above, this figure suggests that income growth in transit-accessible areas was actually 
slightly lower than in other areas, consistent with the information displayed in Figure 5. By the following decade, however, transit accessible neighborhoods saw increases in household income that were 19 percentage points higher than other census tracts. This suggests a lagged effect of transit investment in this decade. This is consistent with anecdotal evidence which suggests that much of the gentrification of these neighborhoods, located along the $14^{\text {th }}$ Street Corridor and in Columbia Heights, did not occur until the early 2000s.

The final figure (Figure 10) examines changes in household income during the most recent decade (2000s). Census tracts near stations that opened during this decade saw increases in household income that were 9 percentage points higher than in other census tracts. Interestingly, census tracts that were accessible to stations opening in the 2000s saw slower household income growth in all previous decades.

The descriptive evidence presented in this section suggests that in all decades but the 1990s, census tracts that were proximate to transit stations opening in the same decade saw higher levels of income growth than other census tracts in the Washington D.C. metropolitan area that were not accessible to transit. We also present evidence of lagged effects and persistence in the timing of transit-induced gentrification, with stations opening in the 1990s experiencing a lagged effect and stations opening earlier experiencing income growth that persisted over time.

\section{Simulation Results}

This section relies on the SILO model to see how housing patterns evolve over time as new transit stations open along the Purple Line in Maryland. We also present the results from the housing policy scenarios discussed in the previous section. 


\section{SIMULATION RESULTS FORTHCOMING}

\section{Conclusion}

This paper examined historical descriptive evidence along with land use forecasts generated by the SILO land use model to examine the impact of housing policies on patterns of sorting by income within the Washington, D.C. metropolitan area. The historical evidence suggests that in most decades when Metro stations were opened, census tracts near transit stations saw higher increases in median household income than other census tracts. We also find evidence that income growth around stations constructed in the 1970s and 1980s persisted over time, while income growth around stations constructed during the 1990s was largest in the following decade. Consistent with other studies (Kahn 2007), we interpret these findings as evidence that some degree of transit-induced gentrification has been occurring in the Washington, D.C. region.

To determine if housing policy interventions can mitigate the degree of transit-induced gentrification and enable low income households to continue living in areas proximate to transit, we examined several policy scenarios using the SILO land use model. [DISCUSSION OF SILO RESULTS FORTHCOMING] 


\section{References}

Alonso, William. 1964. Location and land use. Harvard University Press: Cambridge, MA.

Altshuler, A. and D. Luberoff. 2003. Mega projects: The changing politics of urban public investment. Brookings Institution Press: Washington, DC.

American Public Transit Association. 2010. Transit commuting reported in the American Community Survey. American Public Transit Association, Washington, D.C.

Baum-Snow, N. and M. Kahn. 2005. The effects of urban rail transit expansions: Evidence from sixteen cities, 1970 to 2000. Brookings-Wharton Papers on Urban Affairs, Brookings Institution, Washington DC.

Becker, G.S. 1965. A theory of the allocation of time. Economic Journal 75: 493-508.

Bowes, D. R., K.R. Ihlanfeldt. 2001. Identifying the impacts of rail transit stations on residential property values. Journal of Urban Economics 50: 1-25.

Cervero, Robert, et al. 2004. Transit-oriented development in the United States: Experiences, challenges, and prospects. Transportation Research Board of the National Academies: Washington, DC.

Dawkins, Casey and Ralph Buehler. 2010. Promoting affordable housing near public transit: The role of planning. U.S. Department of Housing and Urban Development, Washington, DC.

Debrezion, G., E. Pels, P. Rietveld. 2007. The impact of railway stations on residential and commercial property values: A meta-analysis. Journal of Real Estate Finance and Economics 35: $161-180$

Domencich, T.A. and D. McFadden. 1975. Urban travel demand. A behavioural analysis. Contributions to Economic Analysis. Vol. 93. North-Holland Publishing: Amsterdam, Oxford.

Federal Transit Administration, U.S. Department of Transportation. 2008. Better coordination of transportation and housing programs to promote affordable housing near transit. Federal Transit Administration, U.S. Department of Transportation, Washington, D.C.

Gatzlaff, D., M. Smith. 1993. The impact of the Miami metrorail on the value of residences station locations. Land Economics 69: 54-66.

Gin, A., J. Sonstelie. 1992. The streetcar and residential location in nineteenth century Philadelphia. Journal of Urban Economics 32: 92-107.

Glaeser, E.L., M.E. Kahn, J. Rappaport. 2008. Why do the poor live in cities? The role of public transportation. Journal of Urban Economics 63: 1-24. 
Harrell, Rodney, Allison Brooks, and Todd Nedwick. 2009. Preserving affordability and access in livable communities: Subsidized housing opportunities near transit and the 50+ population. AARP Public Policy Institute, Washington, D.C.

Hess, Daniel Baldwin and Tangerine Maria Almeida. 2007. Impact of proximity to light rail rapid transit on station-area property values in Buffalo, New York. Urban Studies 44, 5-6: 10411068.

Immergluck, D. 2009. Large redevelopment initiatives, housing values and gentrification: The case of the Atlanta Beltline. Urban Studies 46, 8: 1725-1747.

Kahn, Matthew E. 2007. Gentrification trends in new transit-oriented communities: Evidence from 14 cities that expanded and built rail transit systems. Real Estate Economics 35,2: 155-182.

Knaap, Gerrit J., Chengri Ding, and Lewis D. Hopkins. 2001. Do plans matter? The effects of light rail plans on land values in station areas. Journal of Planning Education and Research 21: 32-39.

LeRoy, S., J. Sonstelie. 1983. Paradise lost and regained: Transportation innovation, income and residential location. Journal of Urban Economics 13: 67-89.

Mayo, S.K. 1980. Theory and estimation in the economics of housing demand. Journal of Urban Economics 10: 95-116.

Mills, Edwin S. 1972. Studies in the structure of the urban economy. Johns Hopkins Press: Baltimore, MD.

Muth, Richard F. 1969. Cities and housing. University of Chicago Press: Chicago, IL.

Pollack, Stephanie, Barry Bluestone, Chase Billingham. 2010. Maintaining diversity in America's transit-rich neighborhoods: Tools for equitable neighborhood change. Dukakis Center for Urban and Regional Policy, Boston, MA.

Pucher, J., J. Renne. 2003. Socioeconomics of urban travel: Evidence from the 2001 NHTS. Transportation Quarterly 57, 3: 49-77.

Thorne-Lyman, Abigail, Alison Nemirow, Jeff Wood, Robert Hickey. 2008. Realizing the potential: One year later. Housing opportunities near transit in a changing market. Center for Transit Oriented Development, Federal Transit Administration, U.S. Department of Transportation, Washington, D.C.

Washington Metropolitan Area Transit Authority. 2010. 2010 Metro media guide. Washington Metropolitan Area Transit Authority, Washington, DC.

Wheaton, W.C. 1977. Income and urban residence: An analysis of consumer demand for location. American Economic Review 67: 620-631. 


\section{Figure 1: Silo Model Design}

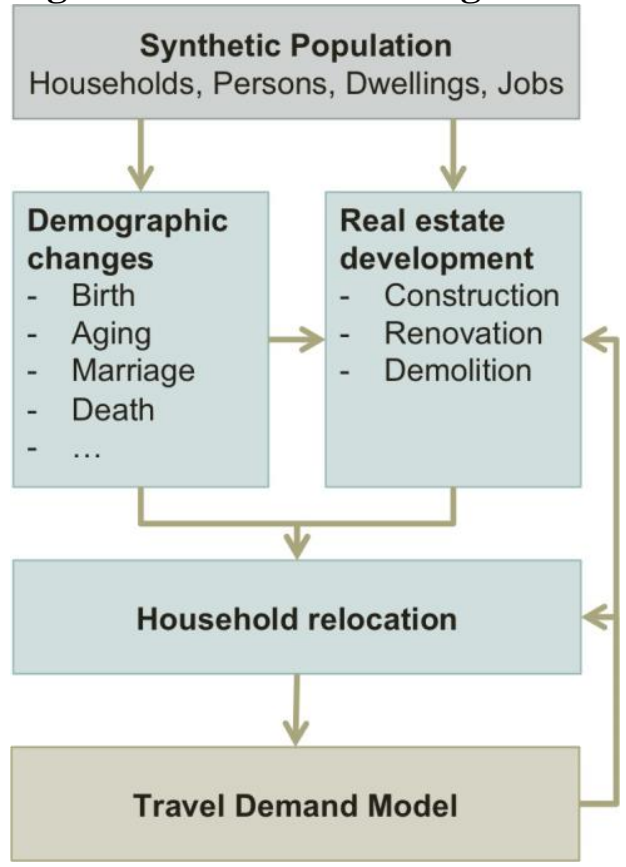


Figure 2

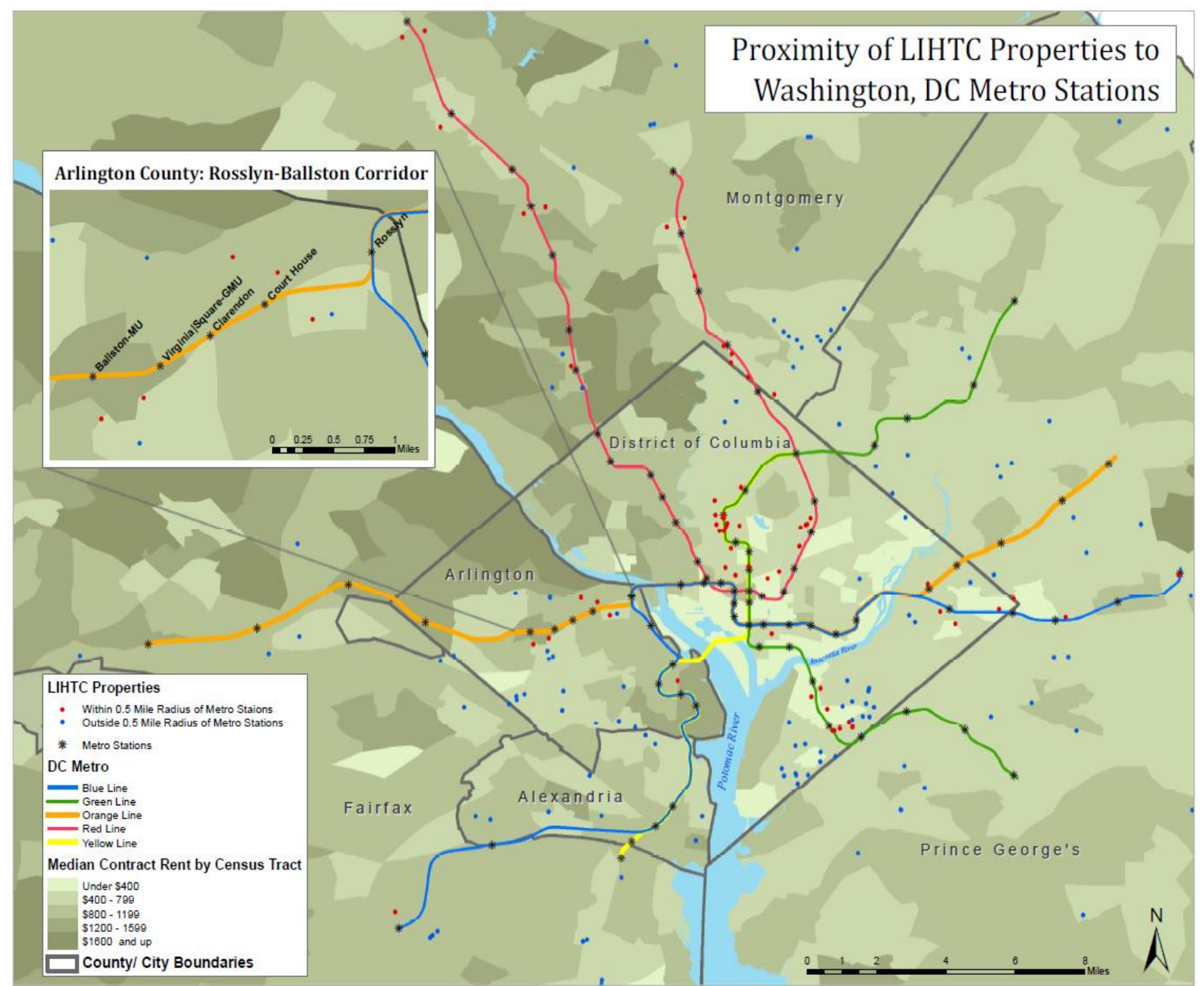

Source: Dawkins and Buehler (2010) 
Figure 3

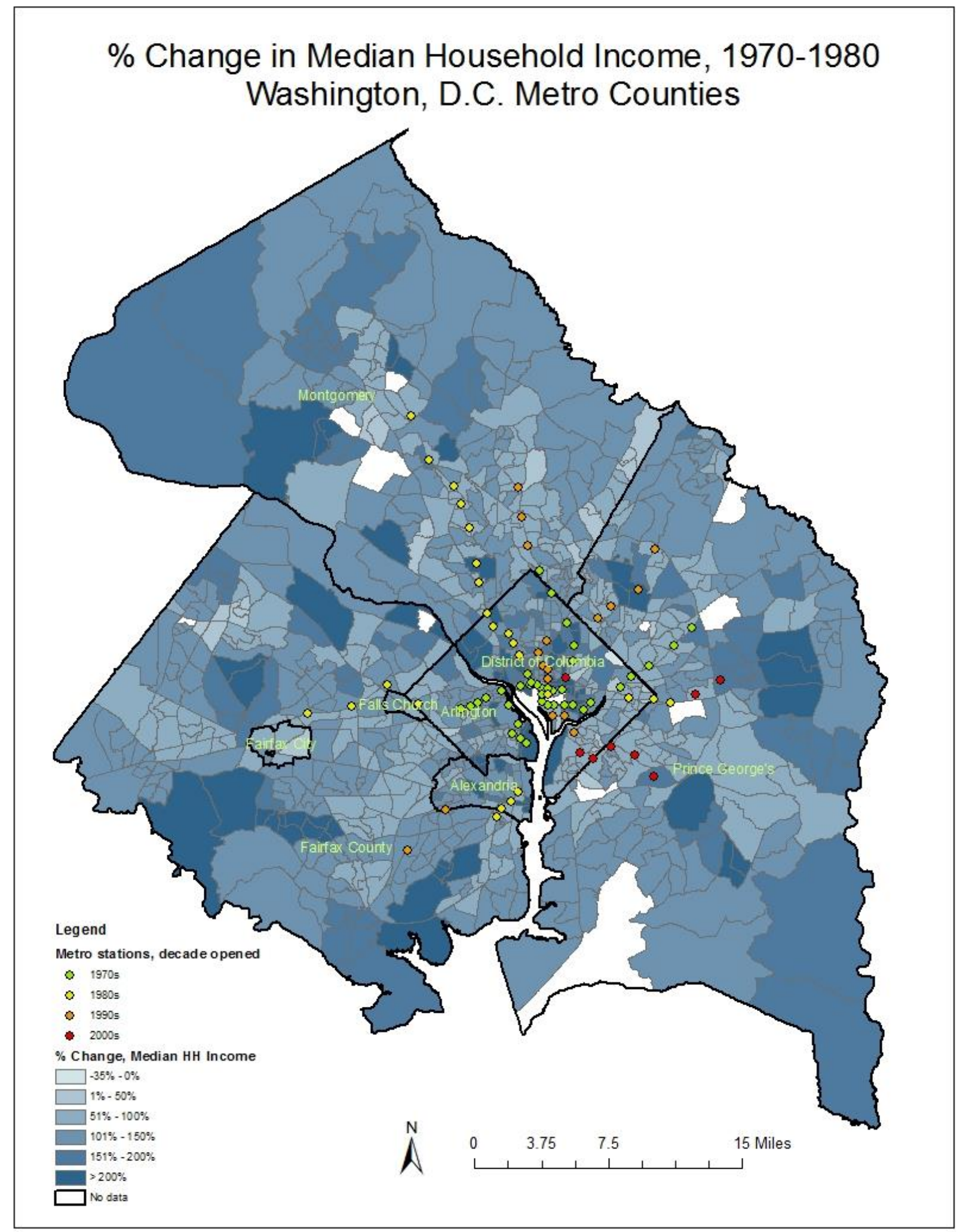


Figure 4

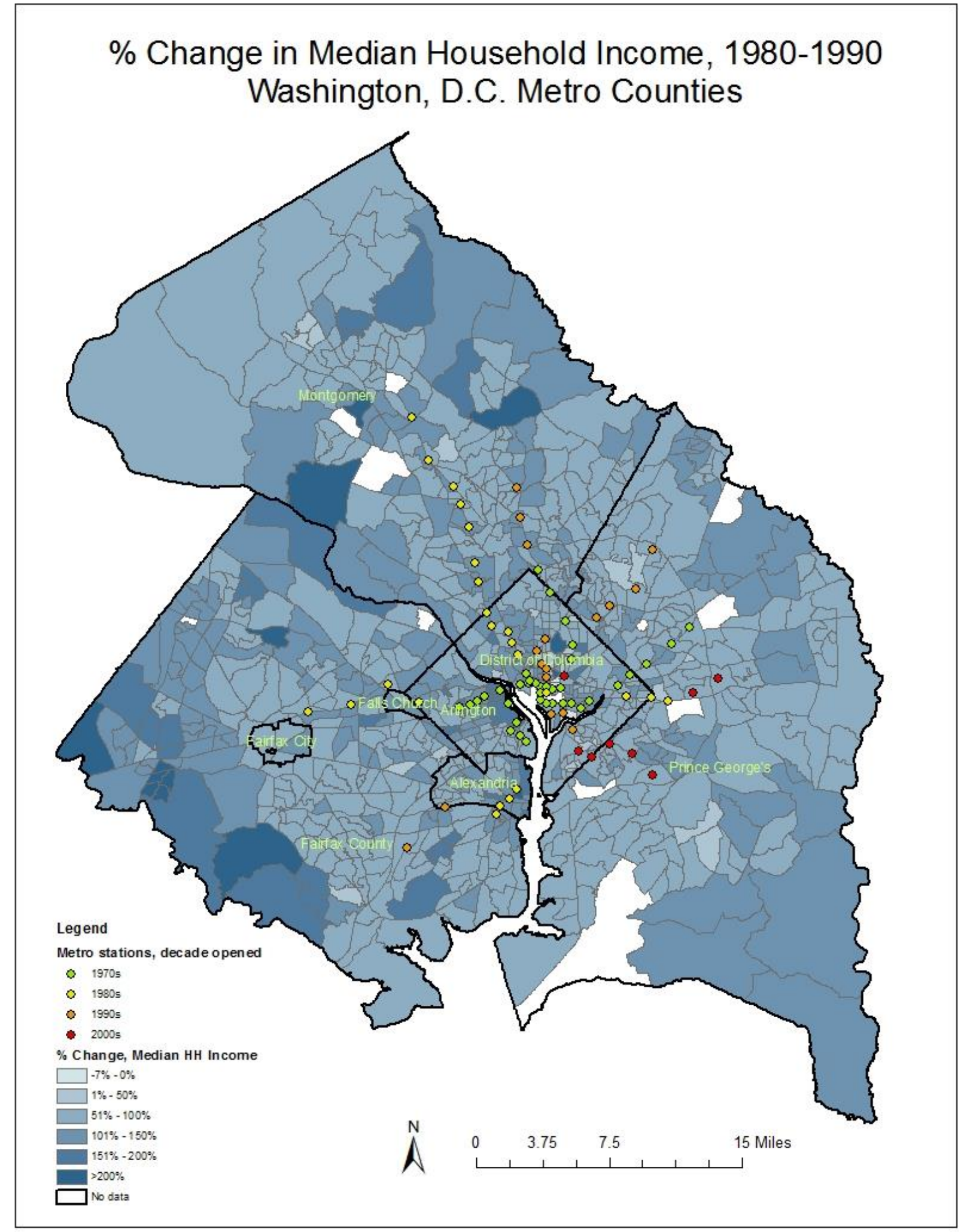


Figure 5

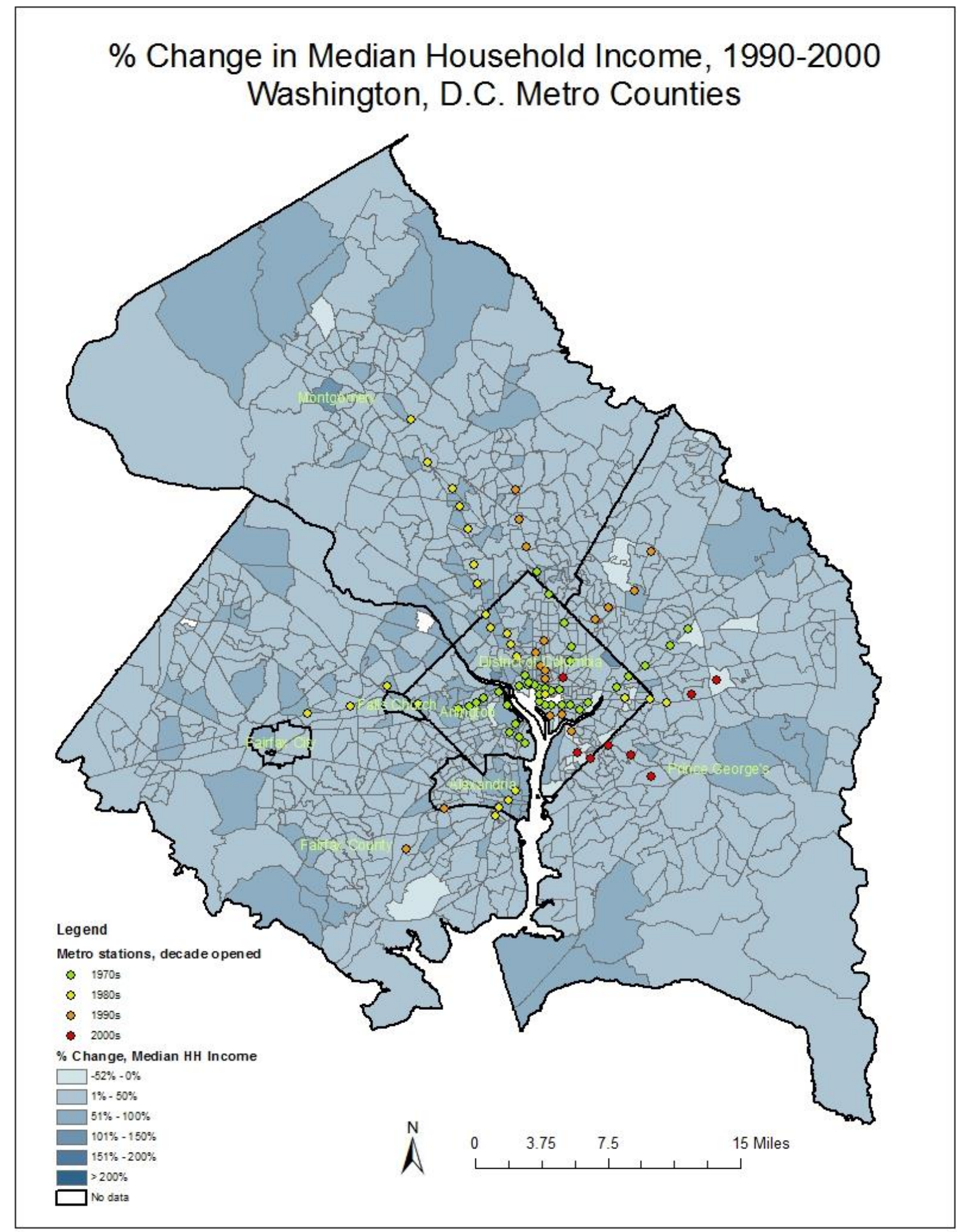


Figure 6

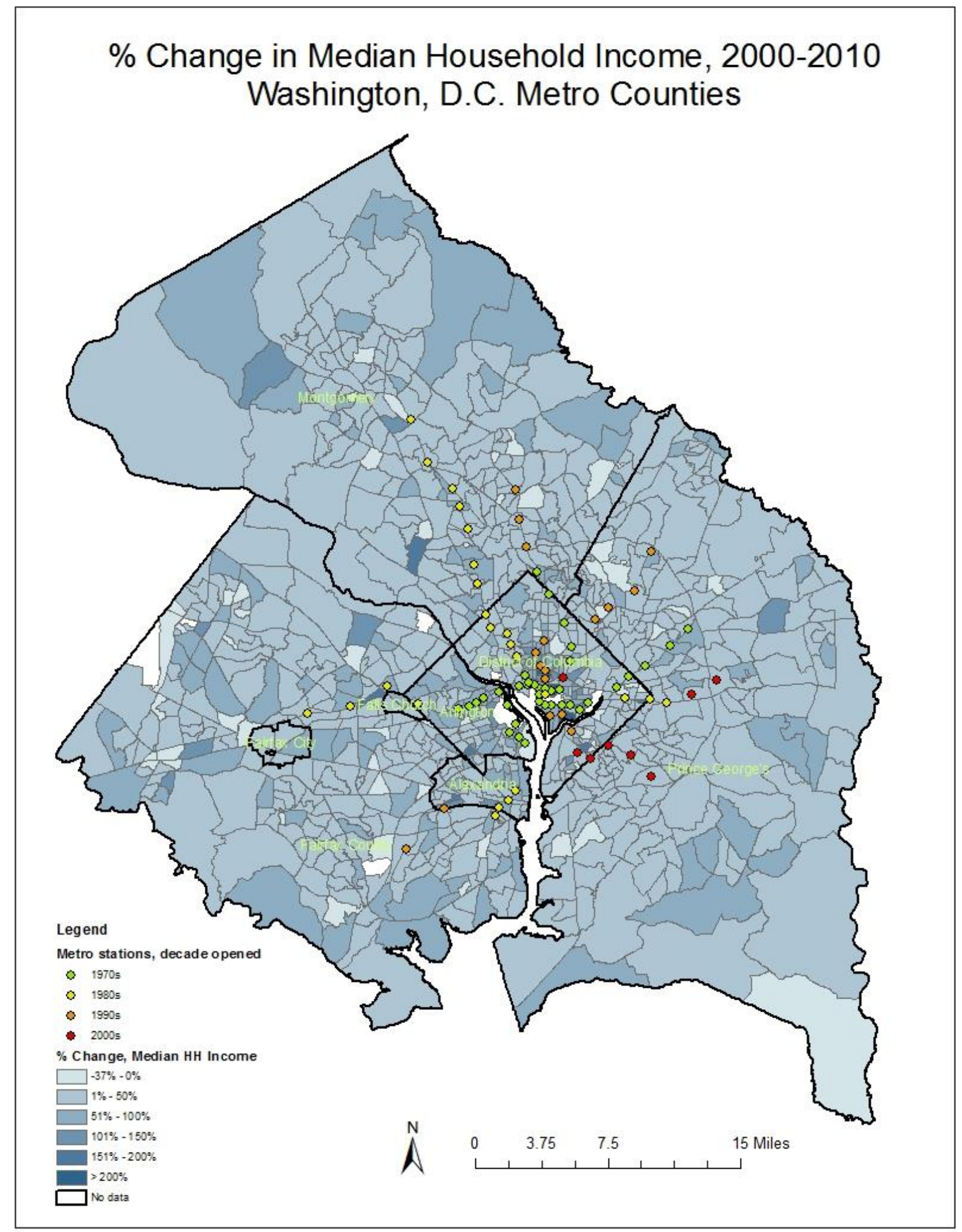


Figure 7

\% Change in Median Household Income,

Washington D.C. Metro Counties, Stations Constructed in 1970s

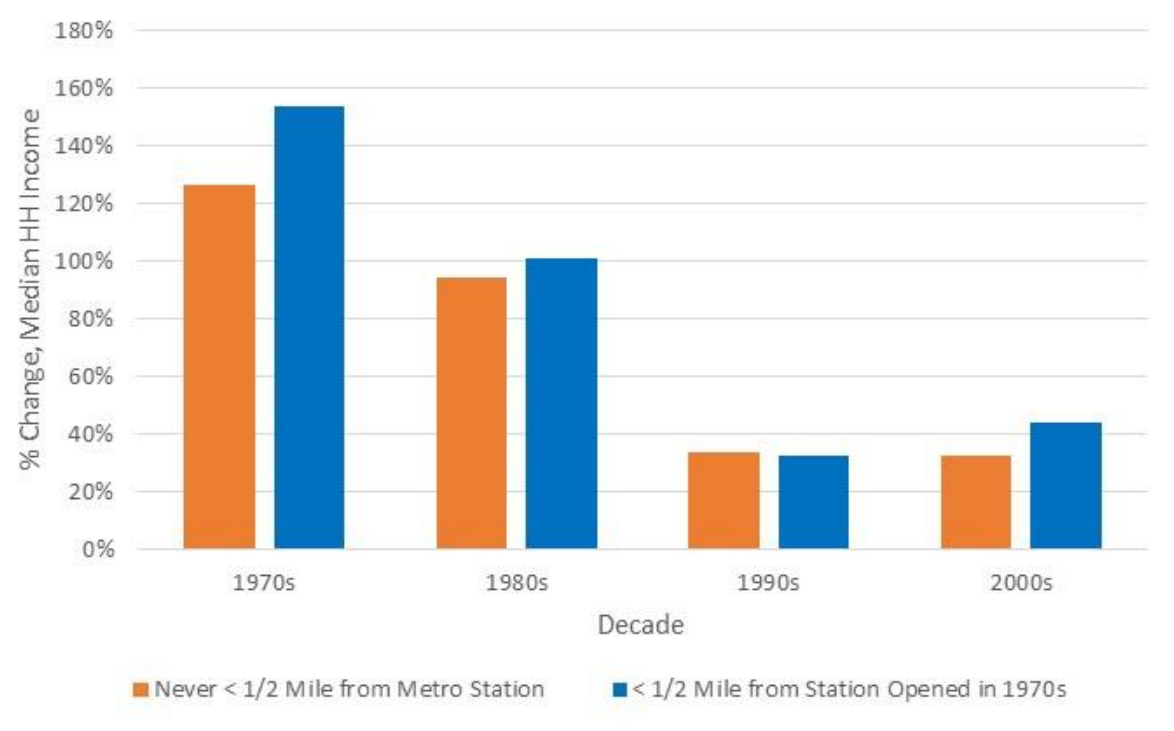

Figure 8

\% Change in Median Household Income,

Washington D.C. Metro Counties,

Stations Constructed in 1980 s

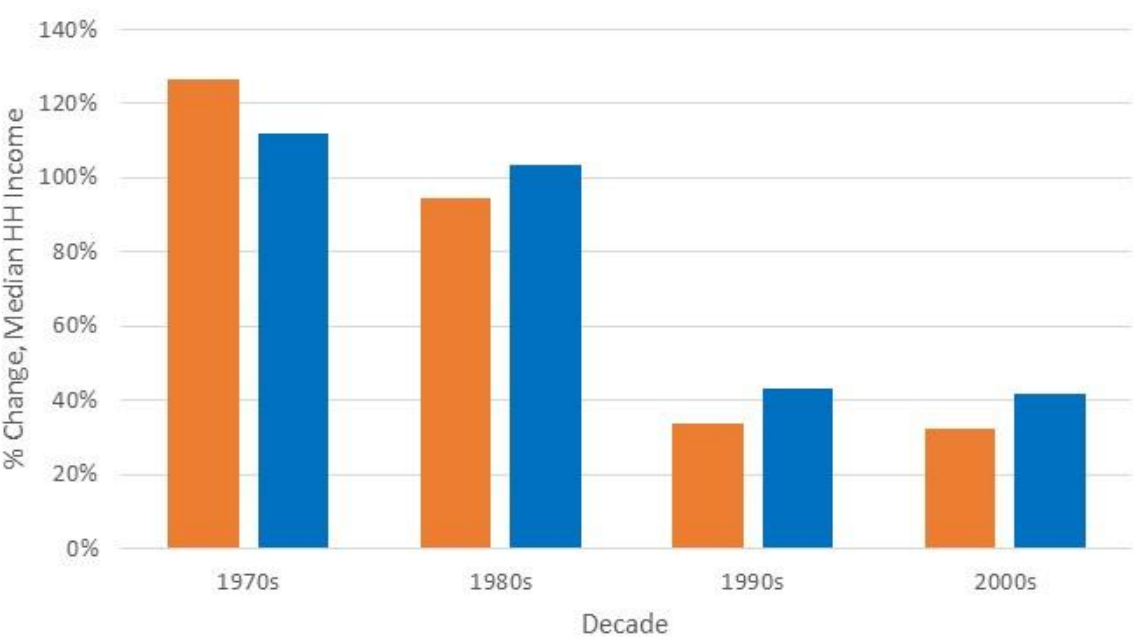

- Never $<1 / 2$ Mile from Metro Station

- $<1 / 2$ Mile from Station Opened in 1980 s 
Figure 9

\section{\% Change in Median Household Income, \\ Washington D.C. Metro Counties, Stations Constructed in 1990s}

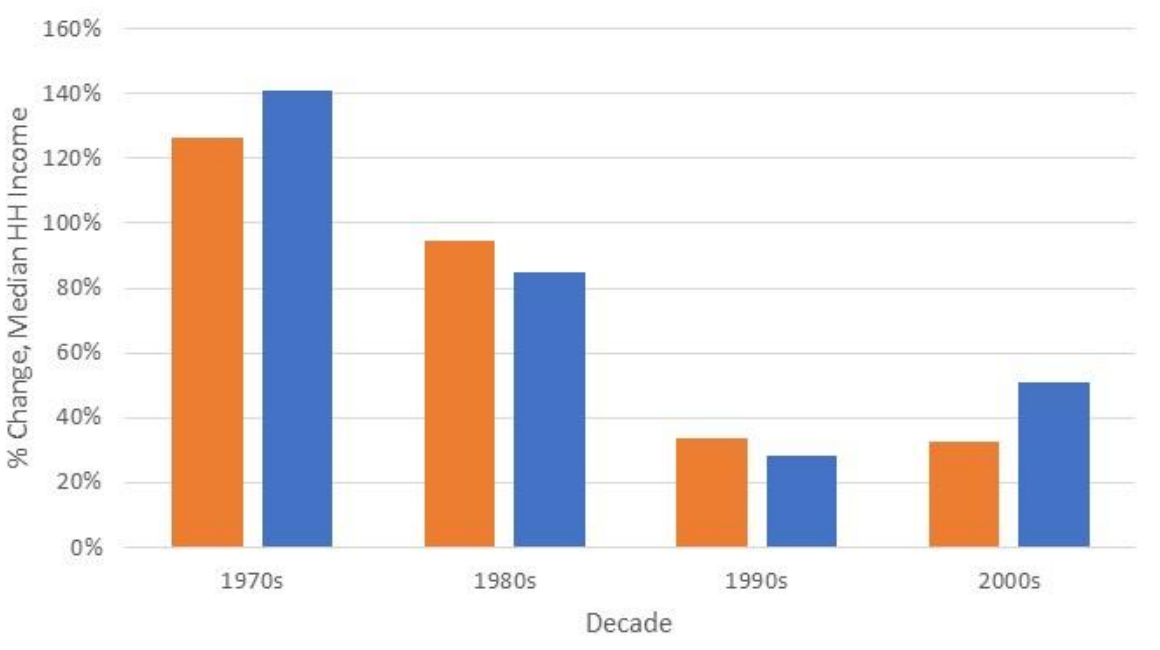

E Never $<1 / 2$ Mile from Metro Station $\quad-\quad<1 / 2$ Mile from Station Opened in $1990 \mathrm{~s}$

\section{Figure 10}

$\%$ Change in Median Household Income,

Washington D.C. Metro Counties,

Stations Constructed in 2000 s

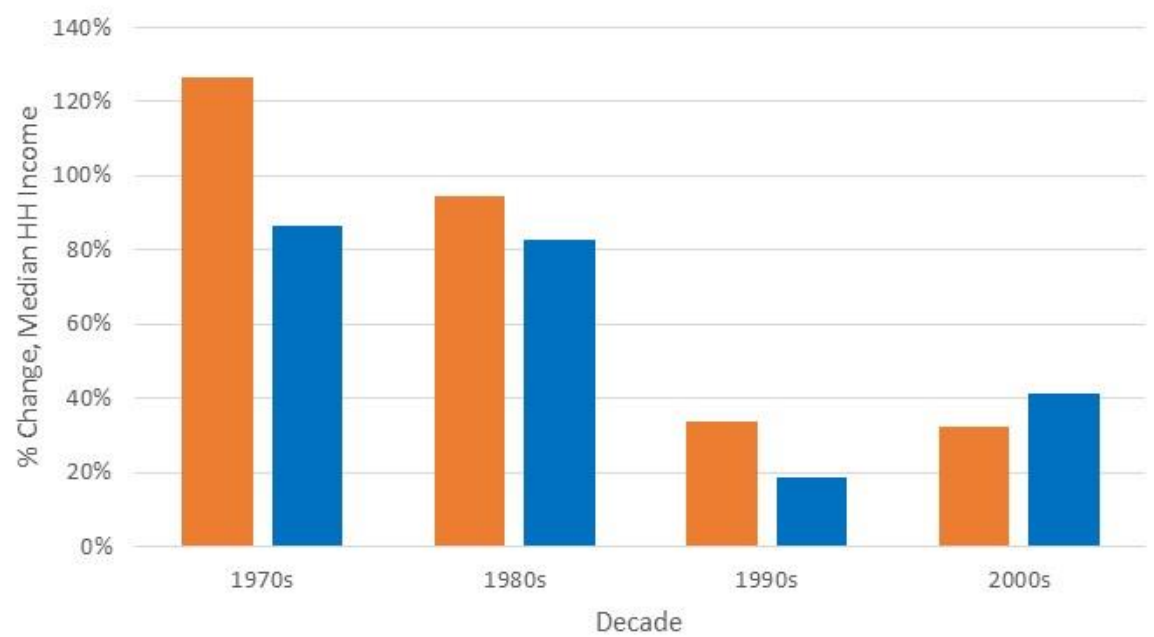

E Never $<1 / 2$ Mile from Metro Station

- $<1 / 2$ Mile from Station Opened in $2000 \mathrm{~s}$ 